University of Nebraska - Lincoln

DigitalCommons@University of Nebraska - Lincoln

USDA National Wildlife Research Center - Staff Publications
U.S. Department of Agriculture: Animal and Plant Health Inspection Service

January 2008

\title{
Mammalian Visitation to Candidate Feral Swine Attractants
}

Tyler A. Campbell

United States Department of Agriculture, Animal and Plant Health Inspection Service, Wildlife Services, National Wildlife Research Center, Texas A\&M University-Kingsville, tcampbell@eastfoundation.net

David B. Long

USDA/APHIS/WS National Wildlife Research Center

Follow this and additional works at: https://digitalcommons.unl.edu/icwdm_usdanwrc

Part of the Environmental Sciences Commons

Campbell, Tyler A. and Long, David B., "Mammalian Visitation to Candidate Feral Swine Attractants" (2008). USDA National Wildlife Research Center - Staff Publications. 781.

https://digitalcommons.unl.edu/icwdm_usdanwrc/781

This Article is brought to you for free and open access by the U.S. Department of Agriculture: Animal and Plant Health Inspection Service at DigitalCommons@University of Nebraska - Lincoln. It has been accepted for inclusion in USDA National Wildlife Research Center - Staff Publications by an authorized administrator of DigitalCommons@University of Nebraska - Lincoln. 


\title{
Mammalian Visitation to Candidate Feral Swine Attractants
}

TYLER A. CAMPBELL, ${ }^{1}$ United States Department of Agriculture, Animal and Plant Health Inspection Service, Wildlife Services, National Wildife Research Center, Texas AEM University-Kingsville, Kingsville, TX 78363, USA

DAVID B. LONG, United States Department of Agriculture, Animal and Plant Health Inspection Service, Wildlife Services, National Wildlife Research Center, Texas A\&M University-Kingsville, Kingsville, TX 78363, USA

\begin{abstract}
Few data exist regarding suitable feral swine (Sus scrofa) attractants in the United States. We compared species-specific visitation and contact rates of mammals to 11 candidate feral swine attractants at scent stations using motion-sensing digital photography to identify promising attractants. We found feral swine had greater visitation rates to apple and strawberry stations than to control stations. We recommend managers consider using strawberry attractants for feral swine-specific applications. If, however, a general feral swine attractant is needed, then apple, berry, or caramel attractants may perform well. (JOURNAL OF WILDLIFE MANAGEMENT 72(1):305-309; 2008)
\end{abstract}

DOI: $10.2193 / 2007-227$

KEY WORDS attractant, bait, collared peccary, feral swine, lure, Pecari tajacu, Procyon lotor, raccoon, Sus scrofa, visitation.

Populations of feral swine (Sus scrofa) are expanding in the United States, where they increasingly cause conflicts with resource managers and landowners (Seward et al. 2004). Tools for controlling feral swine damage include nonlethal (e.g., electric fencing; see Reidy 2007) and lethal (e.g., snare, cage, and corral traps, sport hunting, and aerial shooting) methods (Sweeney et al. 2003). Given the precipitous increase in abundance and distribution of feral swine and subsequent rise in human conflicts, it is apparent that these control methods have not been universally successful (Dickson et al. 2001, Adams et al. 2006). More effective methods to control feral swine damage or modifications to existing methods are needed (Sweeney et al. 2003).

Private landowners, state and federal agencies, and nongovernmental organizations are increasingly faced with the challenge of reducing feral swine damage on their properties cost-effectively. Corn and other grains (both fresh and soured) are widely used as bait in feral swine management (e.g., Matschke 1962, Belden and Frankenberger 1977, Foreyt and Glazener 1979) and research (e.g., Ilse and Hellgren 1995, Gabor et al. 2001, Wyckoff et al. 2005). However, bait consumption by nontarget animals is often high (Hartin 2006), which both directly (e.g., bait loss) and indirectly (e.g., person-hr spent) increases the cost of management. Natural resource managers need speciesspecific attractants to incorporate into management targeting invasive feral swine (Sweeney et al. 2003, Hartin et al. 2007).

The literature is replete with investigations into chemical attractants or lures for other wildlife species in conflict with humans in the United States (e.g., see Roughton 1982, Scrivner et al. 1985, Martin and Fagre 1988, Hein and Andelt 1994, Andelt and Woolley 1996). However, few data exist regarding feral swine attractants (e.g., see Kavanaugh and Linhart 2000, Campbell and Long 2007). The identification of effective attractants would aid in feral swine management by increasing sightability and trapping

${ }^{1}$ E-mail: tyler.a.campbell@aphis.usda.gov efficiency. Additionally, feral swine attractants could be incorporated into oral delivery systems (e.g., bait) to administer pharmaceuticals (e.g., vaccines) to feral swine. In this application, the species-specific characteristics of an attractant may be of paramount importance.

We compared species-specific visitation and contact rates of mammals to scent stations with 11 candidate feral swine attractants in southern Texas, USA. Our objective was to identify promising attractants (i.e., high feral swine visitation and low nontarget visitation) from a suite of candidate attractants. Additionally, we sought to identify temporal trends in visitation to scent stations by feral swine and other mammals.

\section{STUDY AREA}

We conducted our trial on private land in Kleberg County, Texas $\left(27^{\circ} 25^{\prime} \mathrm{N}, 97^{\circ} 35^{\prime} \mathrm{W}\right)$, consisting of 103,691 ha in the eastern Rio Grande Plains ecoregion (Gould 1975). The area was a mixed-shrub rangeland dominated by mesquite (Prosopis glandulosa) and huisache (Acacia farnesiana). The area received an average of $43.6 \mathrm{~cm}$ of precipitation annually, with mean monthly temperatures from March to April of $20.5^{\circ} \mathrm{C}$ and from August to September of $28.2^{\circ} \mathrm{C}$ (National Climatic Data Center 2007). Potential nontarget mammalian wildlife that occurred within the area were collared peccaries (Pecari tajacu), raccoons (Procyon lotor), striped skunks (Mephitis mephitis), opossums (Didelphis virginiana), nine-banded armadillos (Dasypus novemcinctus), badgers (Taxidea taxus), coyotes (Canis latrans), bobcats (Lynx rufus), eastern cottontail rabbits (Sylvilagus floridanus), black-tailed jackrabbits (Lepus californicus), southern plains woodrats (Neotoma micropus), hispid cotton rats (Sigmodon hispidus), and white-tailed deer (Odocoileus virginianus).

\section{METHODS}

Our trials occurred during summer 2006 (Aug-Sep) and during late winter-early spring 2007 (Mar-Apr). We evaluated 11 attractants and one control (12 treatments 
total). Our candidate attractants consisted of liquid domestic swine feed additives, including anise, bubblegum, butterscotch, berry, strawberry, and caramel flavors from QualiTech Incorporated (Chaska, MN) and apple, pig frenzy, cheese, and banana flavors from Marnap Industries Incorporated (Buffalo, NY). Additionally, we included in our trial a treatment of Boarmate ${ }^{\circledR}$ (DuPont Animal Health Solutions, Sudbury, Suffolk, United Kingdom), a synthetic pheromone used to heat-check domestic female hogs for receptiveness to artificial insemination.

We used ported (10 7.9-mm holes/capsule) and capped polyvinyl chloride capsules $(14.0 \times 2.5 \mathrm{~cm})$ to contain attractants. We placed highly absorbent cotton (Procter and Gamble Company, Cincinnati, $\mathrm{OH}$ ) into each capsule and applied $5 \mathrm{~mL}$ of candidate attractant daily at deployment. We placed capsules on the ground, tethered to a $30.5-\mathrm{cm}$ stake. We removed capsules from the field daily to disinfect them and replace the cotton. We used each capsule for only one attractant.

We monitored 12 capsules representing each treatment daily with motion-sensing digital photography (Silent Image Professional Edition; Reconyx, LaCrosse, WI). We placed camera systems $3 \mathrm{~m}$ from capsules and programmed systems to high sensitivity to capture digital images every 2 seconds, for 10 seconds each time the camera system detected animal presence. We deployed scent stations (i.e., one capsule with one attractant and one camera) 2-4 hours before sunset and removed scent stations after 24 hours, at which time we downloaded and stored images. We placed scent stations at $200-\mathrm{m}$ intervals within $30 \mathrm{~m}$ of roadsides and determined orientation relative to the road (right or left side) randomly by flipping a coin. We assigned treatment order, including a control (i.e., tethered capsule with cotton and $5 \mathrm{~mL}$ of distilled water), randomly on a daily basis. During each season (Aug-Sep and Mar-Apr), we monitored each treatment for 30 days (i.e., we used 360 scent stations during each season). In the event of inclement weather, we reset scent stations for an additional 24-hour period.

We determined species-specific visitation and contact rates (e.g., visits/day) at scent stations from digital images. We defined visitation as an individual occurring $\leq 2 \mathrm{~m}$ from capsule with expressed interest in the capsule (e.g., animal looking at capsule). We defined contact as an individual that touched or moved the capsule. Additionally, we recorded time of visitation and other behaviors (e.g., attempted removal of capsule) from images.

We used a Friedman's nonparametric 2-way analysis of variance with preplanned orthogonal contrasts to determine differences between each candidate attractant and the control treatment for daily visitation and contact rates by species using SAS software (SAS Institute, Cary, NC; Dowdy and Wearden 1991). For these models we only included species with $\geq 30$ visits and considered season the blocking factor. We determined statistical significance at $\alpha=$ 0.05 and include test statistics in which $P$-values are $\leq 0.15$, thereby approaching significance and demonstrating trends.
We report mean (SE) visitation and contact rates expressed per 100 days. Additionally, we report temporal visitation to scent stations by feral swine and other mammals. All experimental procedures were approved by the Institutional Animal Care and Use Committee at the National Wildlife Research Center (Permit No. QA-1364).

\section{RESULTS}

We recorded 500 visits and 264 contacts by mammals at scent stations from $>740,000$ digital images. We recorded 189 visits by feral swine, 71 visits by collared peccaries, 67 visits by raccoons, 54 visits by coyotes, 53 visits by whitetailed deer, 28 visits by lagomorphs, 15 visits by bobcats, 10 visits by rodents, 8 visits by armadillos, 4 visits by striped skunks, and one visit by an opossum. Of these, we recorded 118 contacts by feral swine, 44 contacts by raccoons, 43 contacts by collared peccaries, 19 contacts by coyotes, 14 contacts by white-tailed deer, 12 contacts by lagomorphs, 5 contacts by bobcats, 4 contacts by rodents, 2 contacts by armadillos and striped skunks, and one contact by an opossum.

We identified differences in visitation rates to attractants by species. We found feral swine had $325 \%$ and $363 \%$ greater visitation rates to apple $\left(F_{1,707}=6.46, P=0.011\right)$ and strawberry $\left(F_{1,707}=5.84, P=0.016\right)$ stations than to control stations, respectively (Table 1). Additionally, raccoons had $350 \%$ and $325 \%$ greater visitation rates to berry $\left(F_{1,707}=6.16, P=0.013\right)$ and apple $\left(F_{1,707}=4.50, P=\right.$ 0.034) stations than to control stations, respectively. However, collared peccaries visited strawberry stations less often $\left(F_{1,707}=4.52, P=0.034\right)$ than control stations, with no visits recorded. Also, collared peccaries tended to visit butterscotch stations less than $\left(F_{1,707}=3.04, P=0.082\right)$ control stations. We did not find differences in visitation rates between other attractants and control stations by species, although we recorded no visits by raccoons at strawberry stations.

We detected differences in contact rates with attractants by species. We found feral swine had $320 \%$ greater contact rates at apple stations $\left(F_{1,707}=5.64, P=0.018\right)$ than at control stations (Table 1). Furthermore, we observed raccoons had $450 \%$ greater contact rates at berry stations $\left(F_{1,707}=4.50, P=0.034\right)$ than at control stations, and white-tailed deer had $400 \%$ greater contract rates at strawberry stations $\left(F_{1,707}=3.95, P=0.047\right)$ than at control stations. Also, we found feral swine $\left(F_{1,707}=2.60, P\right.$ $=0.108)$ and coyotes $\left(F_{1,707}=3.43, P=0.064\right)$ tended to make contact at strawberry stations more often than at control stations, and raccoons tended to make contact at apple stations more often $\left(F_{1,707}=2.83, P=0.093\right)$ than at control stations. We did not find difference in contact rates between other attractants and control stations by species.

Our temporal trend analyses of visitation data suggested that in August-September, $89 \%$ of feral swine visitations occurred from 2100 hours to 0700 hours, and in MarchApril, $70 \%$ of feral swine visitations occurred from 1900 hours to 2400 hours (Fig. 1). In August-September we 
Table 1. Mean (SE) number of visits (no./100 days) and contacts (no./100 days) with candidate attractants at scent stations by mammals in Kleberg County, Texas, USA from August to September 2006 and March to April 2007.

\begin{tabular}{|c|c|c|c|c|c|c|c|c|c|c|c|c|c|c|c|c|c|c|c|c|}
\hline \multirow[b]{4}{*}{ Attractant } & \multicolumn{20}{|c|}{ Species } \\
\hline & \multicolumn{4}{|c|}{ Feral swine } & \multicolumn{4}{|c|}{ Raccoons } & \multicolumn{4}{|c|}{ Collared peccaries } & \multicolumn{4}{|c|}{ White-tailed deer } & \multicolumn{4}{|c|}{ Coyotes } \\
\hline & \multicolumn{2}{|c|}{ Visit } & \multicolumn{2}{|c|}{ Contact } & \multicolumn{2}{|c|}{ Visit } & \multicolumn{2}{|c|}{ Contact } & \multicolumn{2}{|c|}{ Visit } & \multicolumn{2}{|c|}{ Contact } & \multicolumn{2}{|c|}{ Visit } & \multicolumn{2}{|c|}{ Contact } & \multicolumn{2}{|c|}{ Visit } & \multicolumn{2}{|c|}{ Contact } \\
\hline & $\bar{x}$ & SE & $\bar{x}$ & SE & $\bar{x}$ & SE & $\bar{x}$ & $\mathrm{SE}$ & $\bar{x}$ & SE & $\bar{x}$ & $\mathrm{SE}$ & $\bar{x}$ & $\mathrm{SE}$ & $\bar{x}$ & SE & $\overline{\boldsymbol{x}}$ & $\mathrm{SE}$ & $\overline{\boldsymbol{x}}$ & SE \\
\hline Control & 13 & 4 & 8 & 4 & 7 & 3 & 3 & 2 & 12 & 5 & 7 & 4 & 8 & 4 & 2 & 2 & 3 & 2 & 2 & 2 \\
\hline Strawberry & 48 & 12 & 28 & 9 & 0 & 0 & 0 & 0 & 0 & 0 & 0 & 0 & 13 & 5 & 7 & 3 & 12 & 6 & 7 & 3 \\
\hline Apple & 43 & 10 & 27 & 7 & 22 & 7 & 12 & 5 & 7 & 3 & 2 & 2 & 2 & 2 & 0 & 0 & 8 & 5 & 2 & 2 \\
\hline Berry & 43 & 17 & 32 & 16 & 23 & 7 & 15 & 6 & 10 & 5 & 5 & 4 & 2 & 2 & 0 & 0 & 5 & 4 & 0 & 0 \\
\hline Caramel & 38 & 14 & 27 & 13 & 2 & 2 & 2 & 2 & 7 & 7 & 7 & 7 & 7 & 3 & 5 & 3 & 10 & 5 & 3 & 2 \\
\hline Boarmate & 27 & 10 & 13 & 6 & 3 & 2 & 3 & 2 & 20 & 9 & 15 & 7 & 12 & 5 & 2 & 2 & 3 & 2 & 2 & 2 \\
\hline Banana & 23 & 9 & 13 & 6 & 5 & 3 & 2 & 2 & 10 & 5 & 7 & 3 & 5 & 3 & 2 & 2 & 10 & 5 & 5 & 3 \\
\hline Bubblegum & 20 & 7 & 12 & 4 & 10 & 4 & 7 & 3 & 8 & 4 & 0 & 0 & 8 & 4 & 2 & 2 & 8 & 5 & 3 & 3 \\
\hline Butterscotch & 18 & 7 & 10 & 5 & 8 & 4 & 7 & 4 & 3 & 2 & 3 & 2 & 8 & 4 & 2 & 2 & 8 & 5 & 7 & 5 \\
\hline Cheese & 18 & 8 & 13 & 8 & 10 & 4 & 5 & 3 & 10 & 5 & 3 & 2 & 10 & 4 & 3 & 2 & 10 & 7 & 0 & 0 \\
\hline Pig frenzy & 13 & 5 & 8 & 4 & 8 & 4 & 8 & 4 & 13 & 7 & 8 & 7 & 5 & 4 & 0 & 0 & 8 & 4 & 2 & 2 \\
\hline Anise & 8 & 4 & 5 & 3 & 13 & 6 & 10 & 6 & 18 & 7 & 15 & 7 & 8 & 5 & 0 & 0 & 3 & 2 & 0 & 0 \\
\hline
\end{tabular}

observed feral swine visitation peaked at approximately 0400 hours, and in March-April feral swine visitation peaked at approximately 1900 hours. Our visitation data for other mammals indicated that in August-September, $91 \%$ of other mammal visits occurred from 1800 hours to 0700 hours, and in March-April, $82 \%$ of other mammal visits occurred from 1900 hours to 0700 hours. In August-September we found other mammal visitation peaked at approximately 2100 hours and in March-April other mammal visitation peaked at approximately 0700 hours.

\section{DISCUSSION}

On Ossabaw Island, Georgia, USA, researchers evaluated soured chicken mash (Fletcher et al. 1990), corn oil and meal, and fish oil and meal (Kavanaugh and Linhart 2000) as feral swine attractants. They found high visitation by feral swine and raccoons, one of the few nontarget mammals present on the island (Kavanaugh and Linhart 2000). In southern Texas, researchers found high visitation to manufactured fish- and vegetable-flavored baits by feral swine, raccoons, collared peccaries, coyotes, white-tailed deer, striped skunks, and opossums (Campbell et al. 2006, Campbell and Long 2007). However, these manufactured baits were near-specific to feral swine in Australia (Cowled et al. 2006a, b), which supports fewer omnivorous nontarget mammals. Other researchers in Australia found no differences among creosote, fish stock, meatmeal, molasses, and vanilla as candidate attractants for captive, wild-caught feral swine (Elsworth et al. 2004). Peine and Farmer (1990) reported similar findings for feral swine in the Great Smoky Mountains National Park of Tennessee and North Carolina, USA.

Our visitation rate data indicated that apple and strawberry flavors performed well as feral swine attractants. For example, scent stations containing strawberry attractants were visited by feral swine on approximately half the days deployed. Interestingly, we captured no images in which raccoons or collared peccaries visited or made contact with scent stations containing the strawberry attractant. This is an important finding for management and research applications seeking to minimize nontarget visitation because earlier research found raccoons and collared peccaries to be the major nontarget consumers of baits intended for feral swine within this region (Campbell et al. 2006, Campbell and Long 2007). Also, our observation that apple flavoring was attractive to raccoons indicates that this flavor was not specific to feral swine.

Most of our recorded contacts involved attempted capsule removal or consumption (i.e., capsule in mouth); however, we also observed wallowing, rub-roll, and scent-marking behaviors by feral swine and other mammals. Generally, our contact-rate data agreed with visitation-rate data, with many contacts by feral swine at strawberry, apple, berry, and caramel stations recorded. Our white-tailed deer contact rates indicated that deer made more contacts with the strawberry attractant than with the control. A similar trend was observed for coyotes. This may or may not be a concern depending upon the application, given that deer and coyotes only made contact with strawberry stations on $7 \%$ of deployments.

During August-September and March-April, visitations by both feral swine and other mammals were primarily during nocturnal hours. These measures of activity illustrate the challenges of developing a feral swine-specific attractant, bait, or capture system. Unlike other species in which temporal activity patterns might be exploited (Shivik and Gruver 2002), feral swine share periods of peak activity with other nontarget mammals. However, during March-April, feral swine displayed a distinct peak in visitations at dusk, which preceded most visitations by other mammals. We suggest that management or research applications that use attractants or baits intended for feral swine take measures to ensure their deployment prior to diel peaks-in-activity to minimize nontarget visitation.

Our candidate attractants were comprised of proprietary 


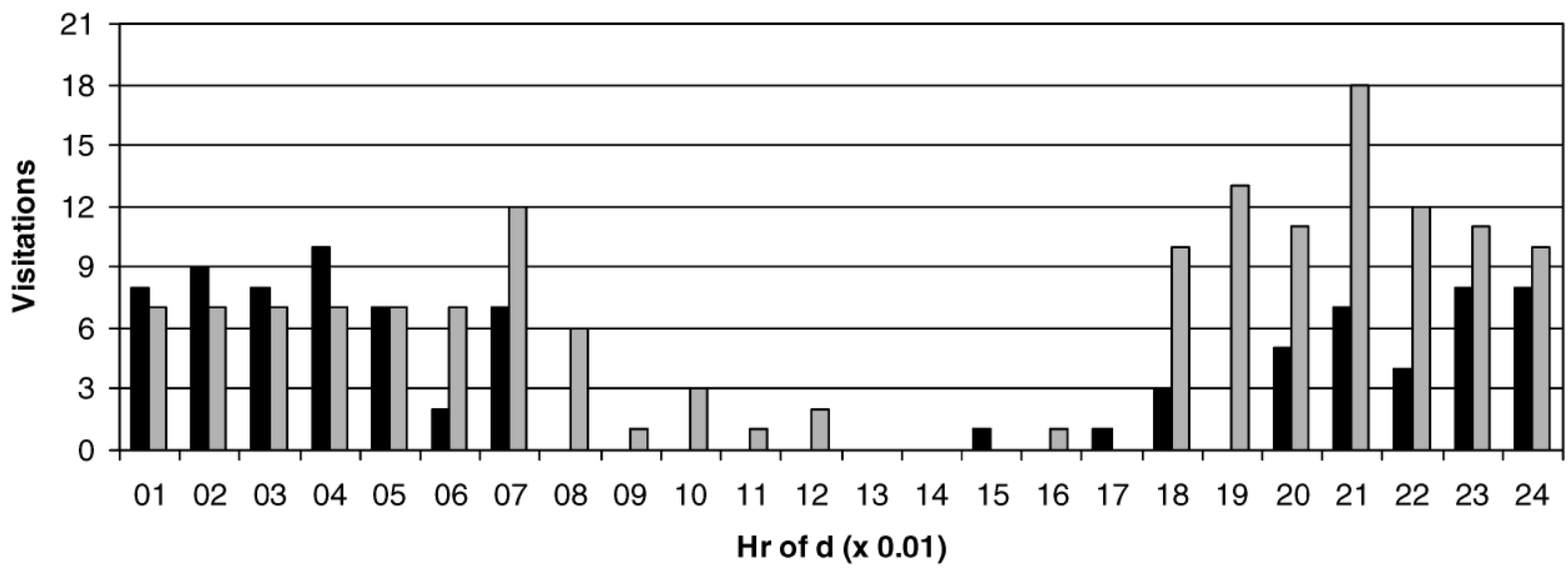

Mar-Apr 2007

Feral swine

$\square$ Other mammals

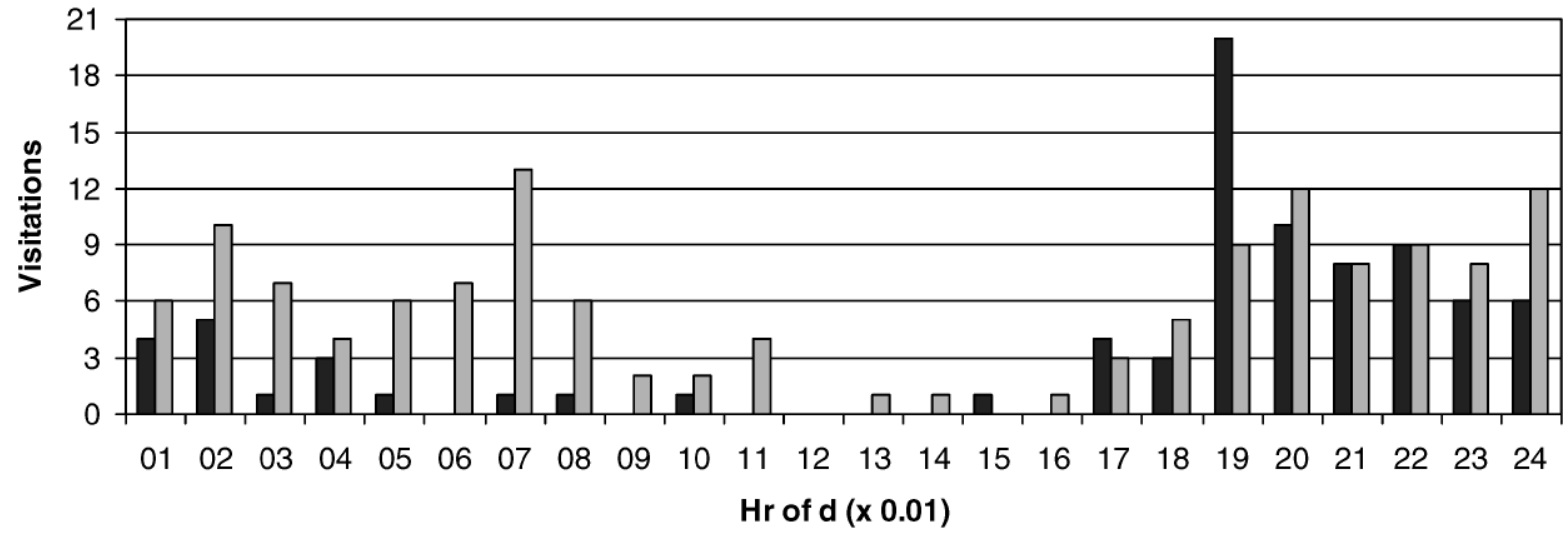

Figure 1. Number of visitations to scent stations by hour of the day for feral swine and other mammals in Kleberg County, Texas, USA, 2006 and 2007. During August-September 2006, sunrise and sunset occurred at approximately 0715 hours and 1945 hours, respectively. During March-April 2007, sunrise and sunset occurred at approximately 0730 hours and 1915 hours, respectively.

formulations of many compounds, in the case of strawberry, mainly ketones, aldehydes, and furanones (K. Brokken, QualiTech Incorporated, personal communication) and were inexpensive (approx. $\$ 10 / \mathrm{L}$ ). It is unknown why raccoons and collared peccaries avoided the strawberry stations yet visited the chemically similar berry stations. However, this behavior was likely caused by a combination of furanones in the strawberry attractant (K. Brokken, personal communication). It is possible that strawberry flavors comprised of other chemical compounds may yield different responses among mammals. Other candidate attractants, such as grape flavoring, scent from female hogs in estrus, and synthetic fermented egg (e.g., FeralMone ${ }^{\mathrm{TM}}$; Pestat Ltd, Bruce ACT, Australia), warrant further evaluation (Choquenot et al. 1993, McIlroy and Gifford 2005, Lapidge et al. 2006).

\section{Management Implications}

We found strawberry flavoring to meet our criteria as a feral swine-specific attractant (i.e., high feral swine visitation and low nontarget visitation). We recommend that natural resource managers consider using strawberry attractants for feral swine-specific applications. If, however, a general feral swine attractant is needed, then apple, berry, or caramel attractants (all with $\geq 292 \%$ more visitations than the control) may perform well.

\section{Acknowledgments}

We thank C. DeYoung and associated lessees for providing access to conduct research. We are grateful to C. Hopkins, H. Parkin, and J. Delgado-Avecedo for their assistance with digital image analysis. Financial support was provided by the United States Department of Agriculture, Animal and Plant Health Inspection Service, Wildlife Services, National Wildlife Research Center. We appreciate the logistical support provided by the Caesar Kleberg Wildlife Research Institute at Texas A\&M University-Kingsville. Our mention of commercial products herein is for identification purposes and does not constitute endorsement or censure by the United States Department of Agriculture. 


\section{LITERATURE CITED}

Adams, C. E., K. J. Lindsey, and S. J. Ash. 2006. Urban wildlife management. Taylor and Francis, Boca Raton, Florida, USA.

Andelt, W. F., and T. P. Woolley. 1996. Responses of urban mammals to odor attractants and a bait-dispensing device. Wildlife Society Bulletin 24:111-118.

Belden, R. C., and W. B. Frankenberger. 1977. A portable root-door hog trap. Proceedings of the Southeastern Association of Fish and Wildlife Agencies 31:123-125.

Campbell, T. A., S. J. Lapidge, and D. B. Long. 2006. Using baits to deliver pharmaceuticals to feral swine in southern Texas. Wildlife Society Bulletin 34:1184-1189.

Campbell, T. A., and D. B. Long. 2007. Species-specific visitation and removal of baits for delivery of pharmaceuticals to feral swine. Journal of Wildlife Diseases 43:485-491.

Choquenot, D., R. J. Kilgour, and B. S. Lukins. 1993. An evaluation of feral pig trapping. Wildlife Research 20:15-22.

Cowled, B. D., E. Gifford, M. Smith, L. Staples, and S. J. Lapidge. $2006 a$. Efficacy of manufactured PIGOUT ${ }^{\circledR}$ baits for localized control of feral pigs in the semi-arid Queensland rangelands. Wildlife Research 33:427437.

Cowled, B. D., S. J. Lapidge, M. Smith, and L. Staples. $2006 b$. Attractiveness of a novel omnivore bait, PIGOUT ${ }^{\circledR}$, to feral pigs (Sus scrofa) and assessment of risks of bait uptake by non-target species. Wildlife Research 33:651-660.

Dickson, J. G., J. J. Mayer, and J. D. Dickson. 2001. Wild hogs. Pages 191208 in J. G. Dickson, editor. Wildlife of southern forests: habitat and management. Hancock House, Blaine, Washington, USA.

Dowdy, S., and S. Wearden. 1991. Statistics for research. John Wiley and Sons, New York, New York, USA.

Elsworth, P. G., J. L. Mitchell, and R. W. Parker. 2004. Evaluation of attractants and toxins for improved target specificity in the control of feral pigs. Queensland Government, Natural Resources and Mines, Robert Wicks Pest Animal Research Centre, Inglewood, Australia.

Fletcher, W. O., T. E. Creekmore, M. S. Smith, and V. F. Nettles. 1990. A field trial to determine the feasibility of delivering oral vaccines to wild swine. Journal of Wildlife Diseases 26:502-510.

Foreyt, W. J., and W. C. Glazener. 1979. A modified box trap for capturing feral hogs and white-tailed deer. Southwestern Naturalist 24:377-380.

Gabor, T. M., E. C. Hellgren, and N. J. Silvy. 2001. Multi-scale habitat partitioning in sympatric suiforms. Journal of Wildlife Management 65: 99-110.

Gould, F. W. 1975. Texas plants—a checklist and ecological summary. Texas Agricultural Experiment Station, Texas A\&M University, College Station, USA.

Hartin, R. E. 2006. Feral hogs—status and distribution in Missouri. Thesis, University of Missouri, Columbia, USA.

Hartin, R. E., M. R. Ryan, and T. A. Campbell. 2007. Distribution and disease prevalence of feral hogs in Missouri. Human-Wildlife Conflicts 1:186-191.

Hein, E. W., and W. F. Andelt. 1994. Evaluation of coyote attractants and an oral delivery device for chemical agents. Wildlife Society Bulletin 22: 651-655.

Ilse, L. M., and E. C. Hellgren. 1995. Resource partitioning in sympatric populations of collared peccaries and feral hogs in southern Texas. Journal of Mammalogy 76:784-799.

Kavanaugh, D. M., and S. B. Linhart. 2000. A modified bait for oral delivery of biological agents to raccoons and feral swine. Journal of Wildlife Diseases 36:86-91.

Lapidge, S., B. Cowled, S. Humphrys, M. Smith, and L. Stapes. 2006. Bacon busting 'down-under', research style. Page 25 in Proceedings of the 2006 National Conference on Wild Pigs, 21-23 May. School of Forestry and Wildlife Sciences, Auburn University, Mobile, Alabama, USA.

Martin, D. J., and D. B. Fagre. 1988. Field evaluation of synthetic coyote attractant. Wildlife Society Bulletin 16:390-396.

Matschke, G. H. 1962. Trapping and handling European wild hogs. Proceedings of the Southeastern Association of Fish and Wildlife Agencies 16:21-24.

McIlroy, J. C., and E. J. Gifford. 2005. Are oestrous feral pigs, Sus scrofa, useful as trapping lures? Wildlife Research 32:605-608.

National Climatic Data Center. 2007. Monthly precipitation and temperature for Kingsville, Texas. National Oceanic and Atmospheric Administration Satellite and Information Service. $<$ http://hurricane.ncdc.noaa. gov/ancsum/ACS >. Accessed 1 May 2007.

Peine, J. D., and J. A. Farmer. 1990. Wild hog management program at Great Smoky Mountains National Park. Proceedings of the Vertebrate Pest Conference 14:221-227.

Reidy, M. M. 2007. The efficacy of electric fencing and population estimation techniques for feral pigs. Thesis, Texas A\&M University, Kingsville, USA.

Roughton, R. D. 1982. A synthetic alternative to fermented egg as a canid attractant. Journal of Wildlife Management 46:230-234.

Scrivner, J. H., W. E. Howard, and R. Teranishi. 1985. The use of digylme as an odor-attractant solvent. Journal of Wildlife Management 49:519521.

Seward, N. W., K. C. VerCauteren, G. W. Witmer, and R. M. Engeman. 2004. Feral swine impacts on agriculture and the environment. Sheep and Goat Research Journal 19:34-40.

Shivik, J. A., and K. S. Gruver. 2002. Animal attendance at coyote trap sites in Texas. Wildlife Society Bulletin 30:502-507.

Sweeney, J. R., J. M. Sweeney, and S. W. Sweeney. 2003. Feral hog Sus scrofa. Pages 1164-1179 in G. A. Feldhamer, B. C. Thompson, and J. A. Chapman, editors. Wild mammals of North America biology, management, and conservation. Second edition. John Hopkins University Press, Baltimore, Maryland, USA.

Wyckoff, A. C., S. E. Henke, T. A. Campbell, D. G. Hewitt, and K. C. VerCauteren. 2005. Preliminary serologic survey of selected diseases and movements of feral swine in Texas. Proceedings of the Wildlife Damage Management Conference 11:23-32.

Associate Editor: McCorquodale. 